\title{
Conflito de Interação Instrumental e Falência Cognitiva no Trabalho Bancário Informatizado
}

\section{Mário César Ferreira}

Professor Dep. de Psicologia Social e do Trabalho da UnB

Doutorando em Ergonomia - EPHE, Paris (Bolsa da CAPES )

Campus da UnB, Asa Norte

Brasilia - DF, CEP 70.910-900

Fax (061) 2738259 e-mail mcesar@unb.fr

Palavras-chaves: trabalho bancário, atividade instrumental, resolução de problema.

Key-words: bank work assisted by computer, activity with instrument, problem solving

\section{RESUMO}

Buscando superar o clássico modelo homem-máquina em ergonomia da informática, argumenta-se neste artigo a pertinência da abordagem Situação de Atividade Instrumental - S.A.I. (Rabardel, 1995) para estudar o trabalho informatizado. A aplicação da abordagem S.A.I. para avaliar uma tarefa bancária (Ordem de Pagamento -OP) colocou em evidência um conflito de interação instrumental tripolar formecendo um quadro explicativo aos indicadores de disfuncionamento constatados na análise da atividade dos bancários $(n=13)$.

\section{ABSTRACT}

Trying to go beyond the classical model of man-machine systems on ergonomics, the aim of this paper is to argue the interest of the Activity Instrument Situation - A.I.S approach (Rabardel, 1995) in computerized work situations. The application of this model on a study of banking task (Payment Order - PO) shows a tripolar instrument interaction conflict. Analyzing the activity of bank clerks ( $n=13)$, the model brings a framework to explain the dysfunction's indicators. 


\section{PRODUÇÃO}

\section{1 - Introdução}

O processo de informatização dos bancos, acelerado a partir dos anos 80 , foi facilitado desde o início pela natureza da atividade bancária. Que natureza é essa? Em uma palavra: o traço transversal característico do conjunto das atividades bancárias é o tratamento de informação contábil alfanumérica, submetido ao clássico imperativo econômico de rentabilidade, produtividade e qualidade. Assim, a matéria-prima do trabalho bancário $^{0}$ é a informação sob a forma predominante de valor monetário. Nesta perspectiva, pode-se dizer que os bancos são verdadeiras indústrias de tratamento de informação. Uma modalidade de informação (cifras e nomes) por natureza algorritimizável, portanto, um pertinente objeto de trabalho para as ciências da computação.

A informática vem sendo, desta forma, - carro-chefe de uma política de modernização bancária que muda o cenário do trabalho nos bancos estabelecendo novas bases na relação de três atores principais: o cliente, o bancário e o banqueiro (Rocha, 1986). Uma modernização que, indo além dos objetivos econômicos, termina por se constituir em uma estratégia de sobrevivência empresarial (Blass, 1992). Todavia, se por um lado estes macro aspectos são portadores de uma certa visibilidade, por outro lado, os efeitos da informatização sobre as atividades dos sujeitos, principalmente em termos de custos humanos e conseqüências sobre o savoir-faire dos bancários são pouco ou mal conhecidos.
A escassa literatura sobre trabalho bancário informatizado parece ter uma vocação para a generalidade (Gollac, 1988; Brument, 1986; Karnas \& Salengros, 1983). Restringindo-se à ponta do iceberg ela tem, entretanto, o mérito de oferecer enormes portas de entrada à investigação de temas de pesquisa mais pontuais. Nesse sentido, a pesquisa realizada por Reuter (1984) serve como ilustração (Quadro 1). Uma das portas de entrada consiste em estudar o estatuto da atividade do(s) bancário(s) com o computador para garantir um tripé bem conhecido: qualidade, rapidez e eficiência. Com efeito, trata-se de um território de pesquisa a desbravar. Entre o débito e o crédito que marca o ritual cotidiano do modo de ser dos bancos, existem outros fatores que ultrapassam largamente 0 paradigma bipolar da interface homemmáquina. A ergonomia da informática tem o que dizer sobre esta questão.

Algumas pesquisas no campo da ergonomia (Valléry \& Chardavoine, 1988; Rogard \& Valléry, 1993), chamam a atenção para o fato que na origem das taxas de erros, do re-trabalho, do desinteresse e da rejeição dos operadores que utilizam o sistema informatizado, encontram-se dois fatores principais: (a) o esgotamento da capacidade cognitiva $\mathrm{e}$ (b) o conseqüente colapso de estratégia operatória para tratar e resolver uma determinada tarefa. Tais deficiências são oriundas, principalmente, da concepção de software/hardware e das exigências técnico-organizacionais da tarefa. 


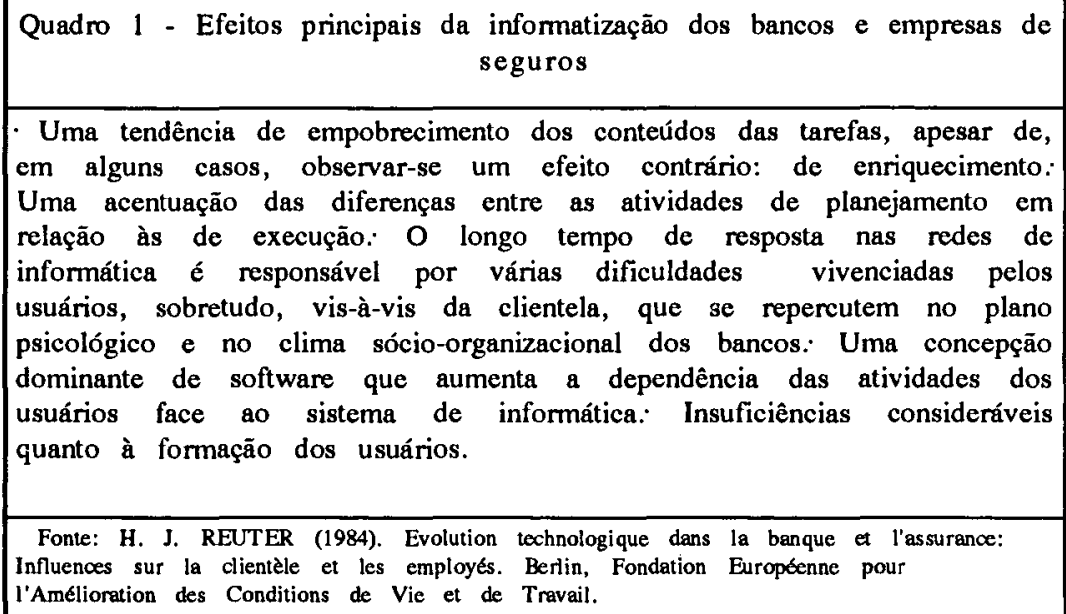

Quadro 1 - Efeitos principais da informatizaçāo dos bancos e empresas de seguros

- Uma tendência de empobrecimento dos conteúdos das tarefas, apesar de, em alguns casos, observar-se um efeito contrário: de enriquecimento: Uma acentuação das diferenças entre as atividades de planejamento em relaçāo às de execução: $O$ longo tempo de resposta nas redes de informática é responsável por várias dificuldades vivenciadas pelos usuários, sobretudo, vis-à-vis da clientela, que se repercutem no plano psicológico e no clima sócio-organizacional dos bancos. Uma concepção dominante de software que aumenta a dependência das atividades dos usuários face ao sistema de informática: Insuficiências consideráveis quanto à formação dos usuários.

Fonte: H. J. REUTER (1984). Evolution technologique dans la banque et l'assuranœ: Influences sur la clientèle et les employés. Berlin, Fondation Europóenne pour l'Amélioration des Conditions de Vie et de Travail.

Desta forma, o modus operandi do usuário parece refém de uma lógica tecnicista de concepção cuja abordagem privilegia o perfeito funcionamento do sistema técnico em detrimento do bemestar do usuário. Para Theureau (1994), esse modo de olhar é um indicador de racionalidade limitada do programador que, visando prevenir dificuldades futuras, constrói paradigmas do senso comum sob a forma de quatro variantes do tecnicismo: (a) "o homem se adaptará"; (b) "é preciso haver normas, a estandardização é um sagrado remédio"; (c) "o que é bom para mim, enquanto programador, é bom para os usuários potenciais"; e (d) "da próxima vez será melhor". Para completar esse ponto de vista da ergonomia vis-à-vis da vertente de coricepção tecnicista é oportuno recuperar uma passagem do artigo de Scapin (1991):

Os programadores parecem mais rigorosos na decomposição da lógica da tarefa do que na consideração efetiva dos conhecimentos, dos procedimentos e dos objetivos dos utilizadores. Na maior parte dos casos, os programadores possuem modelos do usuário que permitem somente responder questões genéricas (...) o contato dos programadores com os usuários é geralmente residual e a variabilidade destes é subestimada.

Esse mesmo autor (Scapin, 1986) assinala, a partir de uma perspectiva ergonômica, os equívocos mais freqüentes de concepção constatados na avaliação de diferentes contextos de trabalho informatizado (Quadro 2). Ele mostra alguns exemplos dos pecados capitais no trabalho de programação. Passados dez anos desde a publicação deste artigo e, não obstante a evolução largamente positiva na prática de concepção, boa parte dos aspectos assinalados por Scapin permanece atual. 


\begin{tabular}{|c|c|}
\hline Quadro 2 - Deficiências principais de con & œepçäo de Interface Homem-Computador (IHC) \\
\hline $\begin{array}{l}\text { Conhecimento prévio insuficiente tanto dos } \\
\text { usuŕrios quanto da tarefa. }\end{array}$ & $\begin{array}{l}\text { Falta de metodologia na concepçăo da Interface } \\
\text { Homem-Computador. }\end{array}$ \\
\hline $\begin{array}{l}\text { Conceber uma interface segundo uma orientação } \\
\text { mais funcional que operacional. }\end{array}$ & $\begin{array}{l}\text { Avaliaçāo imprecisa de consequências } \\
\text { combinatórias das transaçōes de diálogo. }\end{array}$ \\
\hline - Falta de homogeneidade de concepção. & - Nāo prever os possíveis erros humanos. \\
\hline $\begin{array}{l}\text { Programar privilegiando critérios de performance } \\
\text { do sistema que critérios ligados aos objetivos dos } \\
\text { usuários e à exigências técnicas da tarefa. }\end{array}$ & $\begin{array}{l}\text { Näo fornecer todas as informaçōes disponiveis } \\
\text { mas somente aquclas necessárias a tarefa. }\end{array}$ \\
\hline $\begin{array}{l}\text { Fornecer todas as funçōes imagináveis a invés } \\
\text { de privilegiar um conjunto racional e objetivo de } \\
\text { funçóes essenciais. }\end{array}$ & $\begin{array}{l}\text { Considerar o computador como um fim e não } \\
\text { como um meio de trabalho. }\end{array}$ \\
\hline $\begin{array}{l}\text { Utilização inadequada do sistema, contornando } \\
\text { regras e produzindo atalhos face as dificuldades } \\
\text { encontradas para realizar uma operaçăo. }\end{array}$ & $\begin{array}{l}\text { Utilizaçāo parcial do sistema reduzindo-o a um } \\
\text { subconjunto de suas capacidades. }\end{array}$ \\
\hline - Nāo levar em conta a modificação da tarefa. & $\begin{array}{l}\text { Adotar a figura do intermediário entre o usuário } \\
\text { e o sistema (comportamento típico de managers). }\end{array}$ \\
\hline $\begin{array}{l}\text { Fonte: D. L. SCAPIN (1986), Guide ergonomique de conce } \\
\text { 77. INRLA-ROCQUENCOURT. }\end{array}$ & tion des inkerfeces homme-machine. Rapports Tochniques, mo \\
\hline
\end{tabular}

É dentro deste quadro mais geral que se inscreve este texto. Ele aborda uma pesquisa ergonômica de uma tarefa bancária informatizada numa agência situada em Paris, a partir de uma perspectiva teórica de atividade instrumental.

O texto comporta um duplo objetivo: (a) apresentar o modelo Situação de Atividade Instrumental - S.A.I. de Rabardel \& Vérillon (in Rabardel, 1995), com uma abordagem teórica pertinente em ergonomia para avaliar a informatização do trabalho; e, à luz deste modelo; e (b) mostrar que uma concepção tecnicista de interface homem-computador produz, no caso estudado, um conflito de interação instrumental tripolar (bancário - software - objeto da ação). Tal conflito servirá de moldura para contextualizar alguns indicadores de disfuncionamento constatados na análise da atividade sob a modalidade de dificuldades vivenciadas pelos bancários.

\section{2 - O "Modelo S.A.I." como quadro teórico de referência}

O modelo Situação de Atividade Instrumental - S.A.I. elaborado por Rabardel \& Vérillon (Rabardel, 1995) situa-se em uma perspectiva antropocêntrica, ou seja, o homem em atividade de trabalho ocupa lugar central a partir do qual é analisado o sistema técnico. $O$ modelo fundamenta-se no conceito psicológico de instrumento e visa a colocar em evidência o processo mental 
engendrado pelo sujeito que transforma um determinado artefato em um instrumento de trabalho. O termo instrumento, na acepção utilizada por Rabardel, designa um artefato em situação de utilização pelo sujeito, como um meio usado por este para agir sobre o(s) objeto(s) de sua ação. Nesta ótica, o instrumento é portador de quatro propriedades principais: (a) mediação entre o sujeito e o objeto da ação; (b) meio de ação e de atividade oferecendo ao sujeito um arco de possibilidades de ação; (c) operacionalidade na medida que realiza parte do trabalho do sujeito; e (d) portador de experiência acumulada em termos de aquisição cultural da espécie humana.

O conceito de instrumento veicula ainda dois componentes indissociáveis: artefatual e psicológico. O componente artefatual (material ou simbólico) do instrumento é um produto do sujeito ou de outros sujeitos, enquanto que o componente psicológico representa os esquemas cognitivos de utilização (individual ou coletiva) estruturados pelo(s) sujeito(s) que se estabelecem a partir do uso do artefato. Será sempre o uso do artefato por um sujeito ou um coletivo de trabalho que lhe atribui o estatuto de instrumento.

O processo psicológico posto em curso pelo sujeito para utilizar um dado artefato é singular. A partir do conceito de esquema de Piaget (Rabardel, 1995) o autor elabora três noções principais para a compreensão da interação instrumental entre o sujeito, $o$ artefato e o objeto da ação (Quadro 3). A elaboração dos esquemas cognitivos de utilização joga um papel central no processo de instrumentalização. Neste sentido, o instrumento constitui-se, do ponto de vista psicológico, numa produção e numa construção do usuário. Assim, seu uso inscreve-se em uma relação dialética dos componentes onde os esquemas cognitivos de utilização constituem-se em fatores estruturantes da atividade de trabalho do sujeito. Eles são, enfim, as ferramentas psicológicas que guiam e orientam a ação do sujeito na interação instrumental assumindo nesta abordagem um valor heuristico fundamental.

O modelo S.A.I. voltado para estudar diferentes classes de atividades instrumentais é constituido por três pólos: o sujeito (o usuário, o operador); o instrumento (a máquina, a ferramenta); e o objeto de trabalho (matéria-prima, uma peça). Estes pólos estão mergulhados em um ambiente singular que encerra o conjunto de condições que o sujeito deve ter em conta para realizar sua atividade.

Essa abordagem é portadora, como todo modelo teórico, de vantagens e desvantagens. A esquematização tripolar de atividade instrumental não é em si mesma uma novidade, todavia, a análise da literatura nesta temática mostra basicamente duas características: (a) a tendência a excluir um dos pólos mencionados ou mesmo de considerá-lo de modo implícito; e (b) a multiplicidade de definições conceituais dos pólos. A 


\section{PRODUÇÃO}

pertinência deste modelo S.A.I. se prende ao fato dele ser uma ferramenta teórica que suscita a diversidade das relações entre os pólos, evidencia o caráter complexo da interação instrumental e permite superar a abordagem bipolar clássica homem-computador no campo da informática.

Os limites do modelo são ligados à diversidade de instrumentos existentes na situação de trabalho, a variabilidade dos contextos de ação e o fato de que a atividade do sujeito não tem por objetivo utilizar o instrumento em si mesmo, mas adotá-lo como um meio para concretizar uma meta. A adaptação do modelo S.A.I. ao estudo do trabalho bancário informatizado, no caso a atividade Ordem de Pagamento-OP, a partir de diferentes dimensões de análise é apresentado na Fig. 1.

A análise da demanda dos bancários, colocada em perspectiva com o quadro teórico, possibilitou formular a hipótese geral do estudo nos seguintes termos:

Os indicadores de disfuncionamento constatados no trabalho (principalmente os erros e dificuldade de utilização) resultam da impossibilidade do bancário em estruturar sua estratégia operatória para executar a tarefa. Na origem desta falência cognitiva situam-se duas ordens de fatores: (a) a falta de transparência operativa da aplicação em relação às caracteristicas dos usuários e às exigências técnicas da tarefa e (b) os efeitos estruturantes do software aplicação sobre a estratégia operativa do bancário.

\begin{tabular}{|c|c|}
\hline Quadro $\mathbf{3}$ - Atividade & $\begin{array}{c}\text { Instrumental: Modalidades de Esquemas Cognitivos de } \\
\text { Utilização }\end{array}$ \\
\hline Esquemas de Uso & 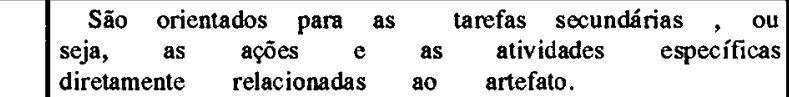 \\
\hline $\begin{array}{l}\text { Esquemas de Ação } \\
\text { Instrumental }\end{array}$ & 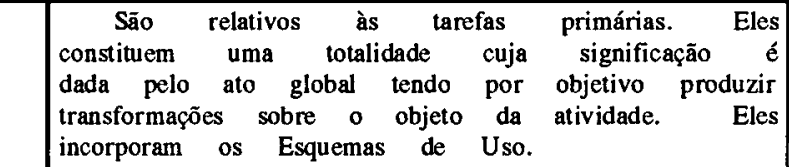 \\
\hline $\begin{array}{l}\text { Esquemas de Atividade } \\
\text { Coletiva }\end{array}$ & 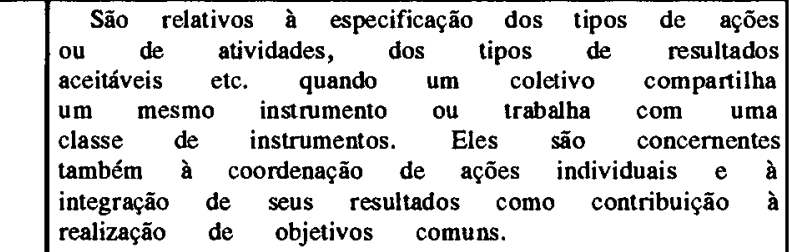 \\
\hline $\begin{array}{ccc}\text { Fonte: } & \text { P. } & \text { RABARDEL } \\
\text { instruments } & (1995), \\
\text { contemporains. } & \text { Armand }\end{array}$ & 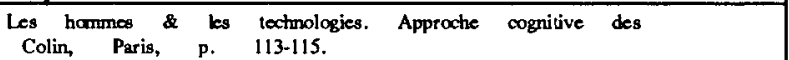 \\
\hline
\end{tabular}


Figura 1 - Dimensóes de Análise da "Ordem de Pagamento" como atividzule buncéria instrumental

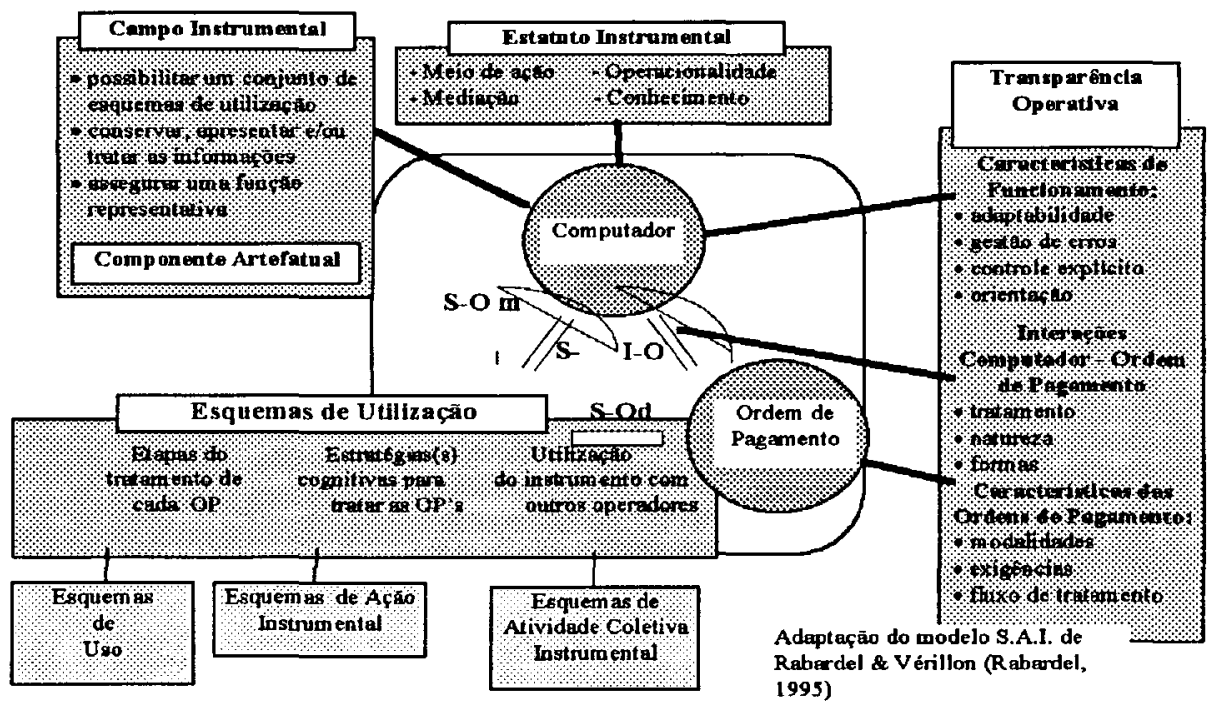

Esta hipótese serviu de guia para o estudo do trabalho bancário informatizado. Antes de apresentar alguns dos principais resultados obtidos pela pesquisa é pertinente descrever suas características metodológicas.

\section{3 - O trajeto metodológico da pesquisa}

A abordagem metodológica em ergonomia se caracteriza por uma flexibilidade procedimental, não existem etapas predefinidas ou caminho rígido a seguir (Guérin; et al 1993). Dois paradigmas principais sustentam a produção de conhecimento em ergonomia e possuem um valor heurístico central: (a) a análise da atividade do sujeito em situação real de trabalho; e (b) a variabilidade dos sujeitos.
O presente estudo foi realizado em uma agência de um banco estrangeiro instalado em Paris, desde os anos 70. Participaram da pesquisa 13 bancários do setor atendimento da agência $(n=42$ funcionários). $O$ processo de informatização das atividades da agência remonta à sua instalação, cuja evolução buscou se adaptar às necessidades impostas pelas mudanças conjunturais. $\mathrm{O}$ perfil dos bancários do setor é o seguinte: a maioria pertence ao sexo feminino (11/ 13); $3 / 4$ com idade entre 41 e 55 anos e tempo de profissão entre 11 e 25 anos. Dois aspectos chamam atenção neste perfil: tendência a homogeneidade sócioprofissional e uma experiência significativa de trabalho.

Em face da inexistência de descrição formal de tarefas, um método específico foi operacionalizado (Ferreira \& Weill- 
Fassina, 1996) a fim de colocar em evidência a representação que os bancários fazem das tarefas em termos de esquemas cognitivos para a ação (Sébillote, 1993). A análise de tais esquemas cognitivos permitiu, ao mesmo tempo, definir critérios objetivos para a escolha da tarefa (Ordem de Pagamento OP) destinada à análise da atividade e estabelecer pistas para o desenvolvimento da pesquisa. A Fig. 2 mostra resumidamente o trajeto percorrido pela pesquisa. Tal trajeto deve ser entendido como uma sistematizaço a posteriori, um esforço de recuperar o caminho percorrido em função dos objetivos, das informações levantadas, dos instrumentos de pesquisa utilizados etc. As flechas em duplo sentido mostram a dinâmica da flexibilidade instrumental que alimenta e (re)elabora as hipóteses.

4 - Resultados e discussão: $O$ papel paradoxal do computador (ajuda e dificuldade) na execução da tarefa

Apresentaremos aqui alguns resultados obtidos pela pesquisa que são ilustrativos da interação instrumental entre o bancário, o software e a tarefa (OP). A tarefa Ordem de Pagamento OP pode ser definida como uma operação financeira pela qual um cliente, pelo intermédio de um documento contábil (formulário), autoriza o banco a creditar a favor de um terceiro um certo valor monetário.

O tratamento das OP's comporta três etapas principais (Fig. 3). Utilizando o computador, quatro bancários encarregados das OP's tratam as informações de cada OP, mudando as informações para atribuir significação monetária a esta modalidade de operação financeira.

De inicio, as informações alimentam o computador transformando-se em representações artificiais; em seguida, elas saem sob a forma de listas que serão objeto de verificação (momento privilegiado para identificar e corrigir os erros cometidos); e, por último, após correções eventuais, o processo de tratamento das OP's é validado no final da jornada de trabalho.

A análise da atividade mostra que o computador ocupa um lugar central para a execução da tarefa influenciando o modo como o bancário tria, prepara e organiza manualmente as informações antes de fazer uso do mesmo. Neste sentido, o uso do computador e as características de funcionamento do software têm um papel estruturador da estratégia cognitiva do bancário. Tratar rapidamente e eficientemente uma OP implica em responder, principalmente, exigências de duas ordens: (a) o funcionamento do software destinado ao tratamento das OP's que dita uma lógica e veicula uma organização do trabalho; e (b) as formalidades da operação financeira (por exemplo, a data de valor). 
Figura 2 - Esboço do trajeto metodológico da pesquisa

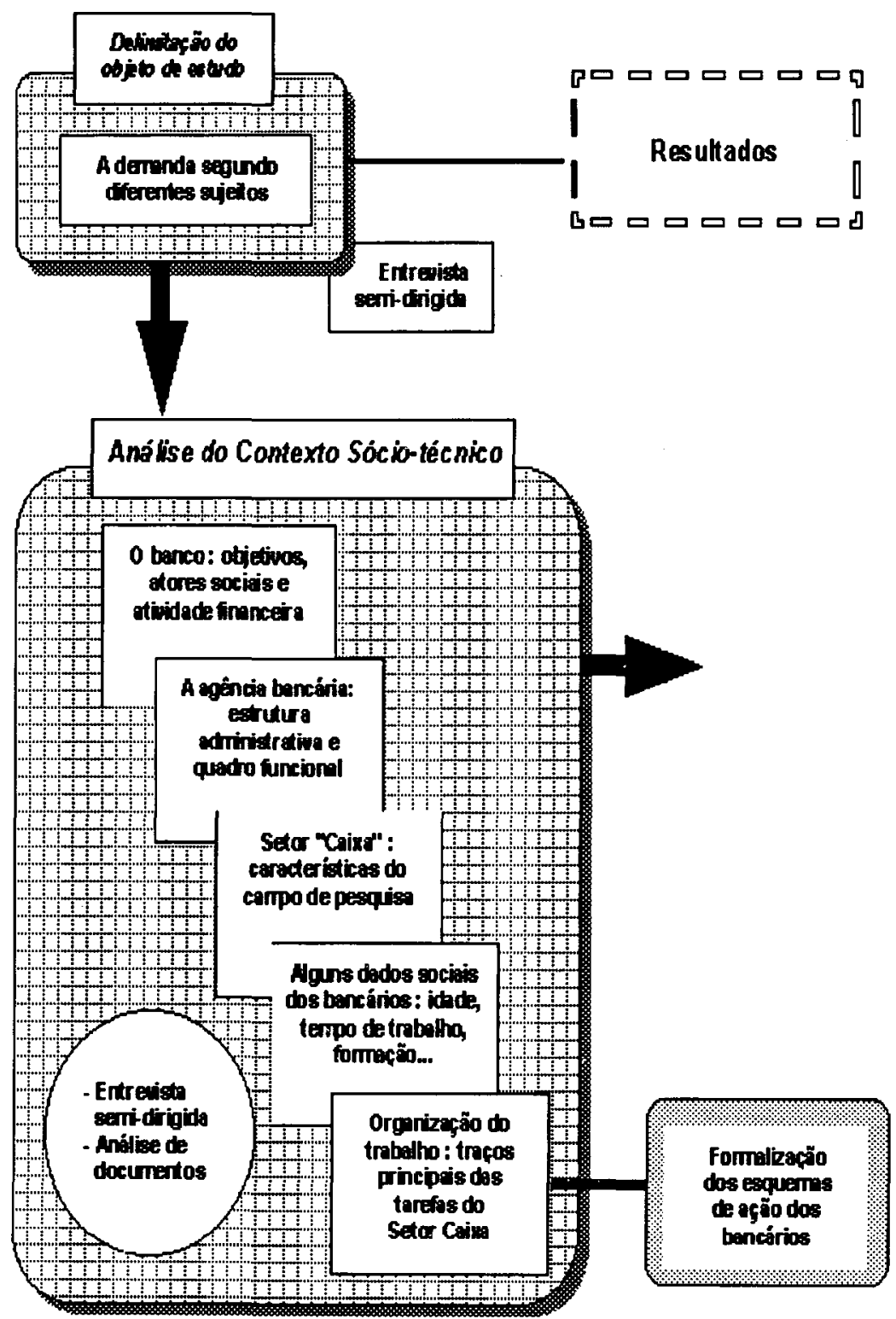




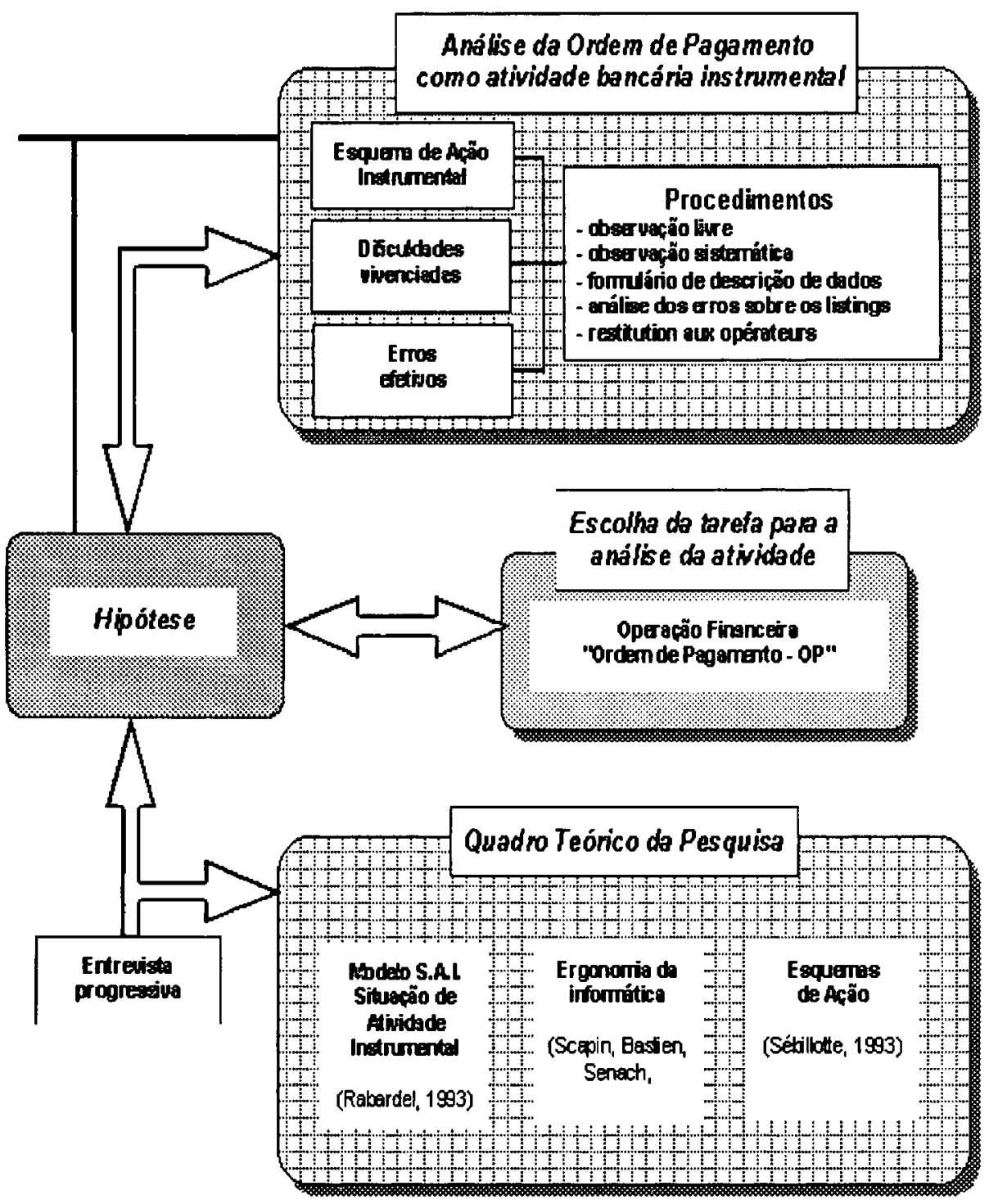


Figura 3 - Etapas principais do tratamento das Ordens de Pagamento

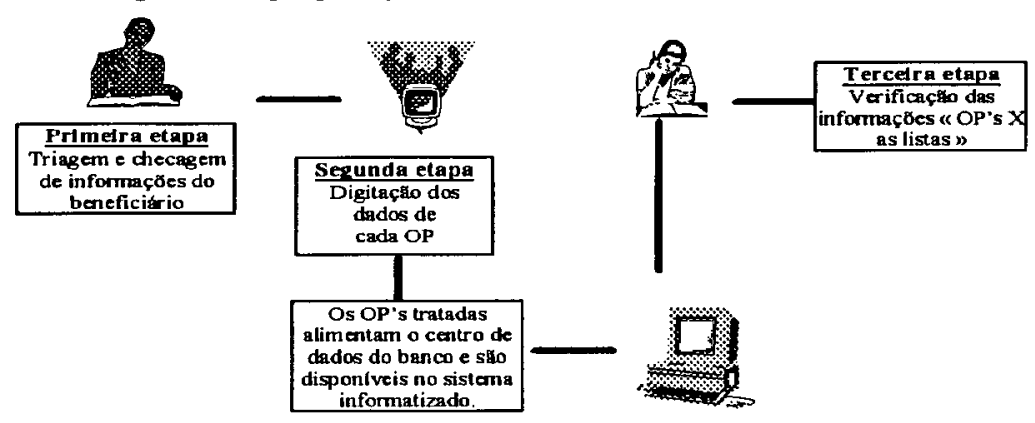

Além dos aspectos da ajuda operacional que o computador aporta ao trabalho do bancário (por exemplo, cálculos matemáticos necessários) foi possivel constatar dois grupos de indicadores de disfuncionamento. De um lado, um conjunto de dificuldades para regular a interação bancário-softwareordem de pagamento e, de outro lado, os erros cometidos no curso da atividade. Ambos os aspectos colocam em cheque: a performance e o bem estar do bancário que busca executar a contento o seu trabalho.

Quanto às principais dificuldades, constatou-se vários aspectos críticos relacionados à lógica de funcionamento do software que são fontes de queixas dos bancários e aumentam a probabilidade da ocorrência de erros na execução da tarefa. Dentre eles, destacam-se:

(a) preenchimento obrigatório de certos campos de informação da tela (por exemplo, o campo motivo da OP enquanto que em alguns tipos de $O P$ essa informação é desnecessária);

(b) longo caminho para identificar uma informação do cliente (por exemplo, a busca por ordem alfabética do nome de um cliente obriga a reiniciar os mesmos procedimentos para cada cliente não deixando margem para atalhos de acesso);

(c) inversão de teclas de comando (por exemplo, no Menu Caixa 20 a tecla F5 serve para 0 acesso rápido às informações do cliente e a tecla F6 serve a função de busca enquanto que no Menu Caixa 30 as funções de tais teclas de comando aparecem invertidas);

(d) tamanho insuficiente de alguns campos de informação nas telas (por exemplo, o campo motivo do Menu 20 não é compativel à exigência técnica da tarefa pois uma OP, por exemplo do tipo "Lettre Chèque", obriga o bancário a fazer um esforço cognitivo suplementar em termos de tentativas de abreviação); e 
(e) cerca de $35 \%$ das teclas de comando do Menu Caixa 32 não são absolutamente utilizadas, neste caso, afirmam os bancários: "elas não servem para nada, jamais utilizamos", o que evidencia o uso parcial do sistema (Scapin, 1986).

Tais dificuldades vivenciadas pelos bancários mostram que a concepção do software, sobretudo, em termos de lógica de funcionamento se distancia das características técnicas implícitas ao tratamento das OP's e da experiência e necessidades dos bäncários. Neste sentido, a transparência do funcionamento do software constitui-se uma dimensão critica do trabalho.

A interação instrumental transformase, neste caso, em sério obstáculo de incompatibilidade a superar. A impossibilidade de superação pode estar na base de performances medíocres e da produção de erros (Bastien, 1991). A análise da apresentação de informações no software mostra também uma falta de homogeneidade e de coerência quanto às formas de denominação e codificação na relação entre o software e o objeto da ação (OP).

Todavia, um outro exemplo constatado pela análise ergonômica do trabalho traz à luz uma das principais dificuldades dos bancários para estruturar a sua estratégia cognitiva em termos de esquema cognitivo de utilização face às exigências da tarefa e às características de funcionamento do software. Tal dificuldade toma a forma de um conflito de interação instrumental entre os pólos do modelo S.A.I. (Rabardel,
1995), ilustrado aqui pelo caso de um bancário.

A Fig. 4 apresenta esquematicamente o conflito de interação instrumental em termos dos movimentos e dos efeitos topológicos segundo a posição das informações das OP's. O que efetivamente se passa?

O conflito instrumental ocorre em três atos. Num primeiro momento, manualmente o bancário constrói sua estratégia operatória estabelecendo movimentos ordenados para identificar espacialmente as informações necessárias a fim de classificar e tratar cada OP. $O$ que preside sua ação são as exigências técnicas da tarefa, por exemplo verificar prioritariamente o valor e o tipo de moeda de uma OP. Num segundo momento, o bancário passa a utilizar o computador para digitar as informações de cada OP. Neste caso, os movimentos de identificação das informações pelo bancário são subordinados à disposição espacial estabelecida pelo software. Aqui o que preside sua ação, ou seja, seu esquema cognitivo de ação instrumental é a lógica estrutural do software, ou seja do programador, que termina por reorientar e reorganizar o objeto de sua ação (OP). Finalmente, num terceiro momento, quando o bancário realiza manualmente o trabalho de verificação, de checagem das informações "OP's $X$ listings", do mesmo modo, os movimentos do bancário são subordinados em função da organização espacial dos dados presentes no listing cuja disposição e apresentação são predefinidas pelo software bancário. 


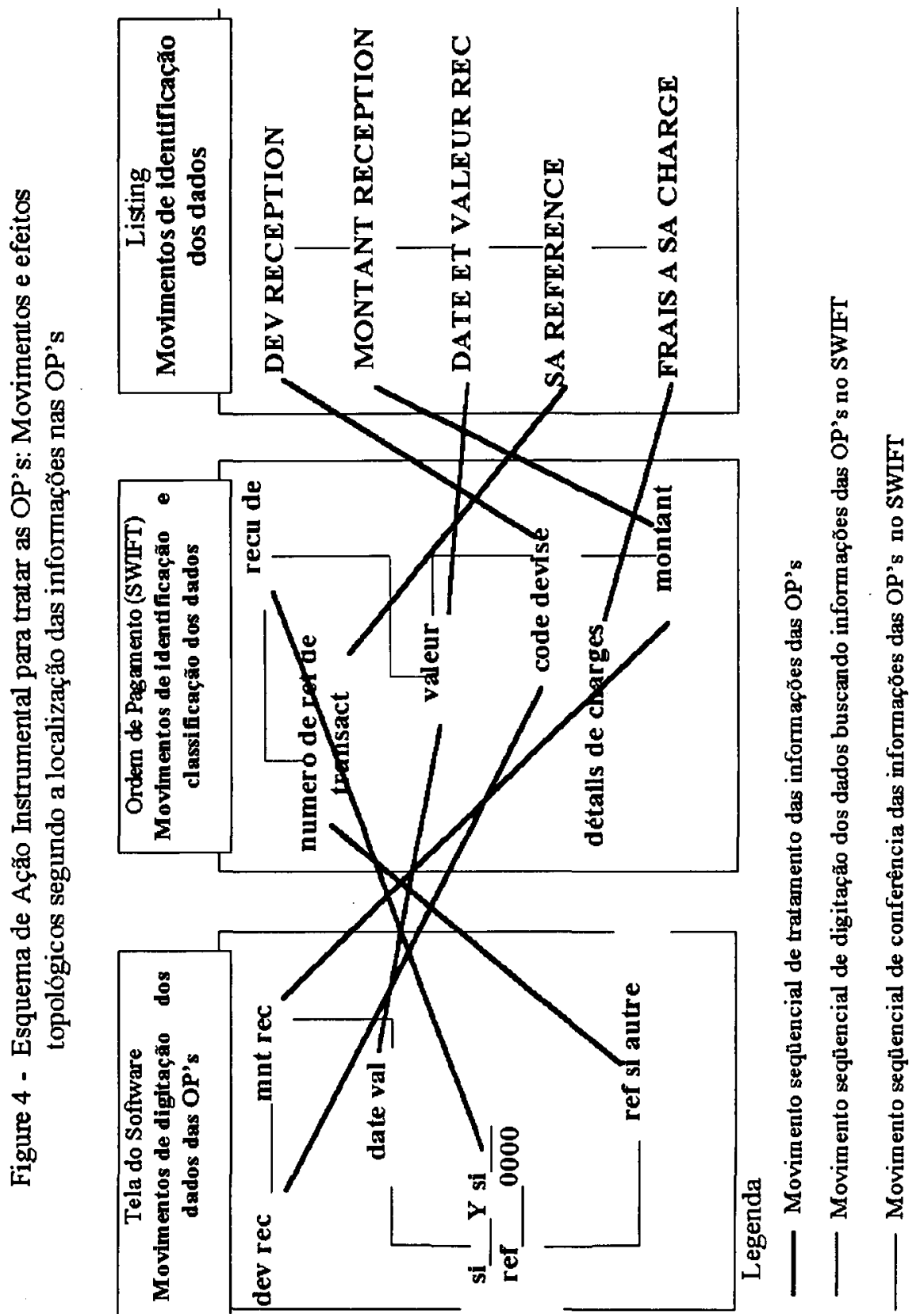




\section{PRODUÇÃO}

O conflito de interação instrumental se instala neste trajeto. $O$ cruzamento de movimentos necessários, seja para digitar, seja para verificar as informações, faz emergir um conflito de interação instrumental bancário-software-OP em função dos efeitos de posição das informações. $O$ bancário se vê obrigado a fazer vários movimentos em direções contraditórias para encontrar e identificar a informação desejada, o que dificulta a estruturação de sua estratégia cognitiva de tratamento de informações.

A tendência progressiva de estabilização das estratégias de exploração visual das informações (Scapin in Karnas et al. 1987) torna-se, neste caso, dificil e às vezes impossivel, tornando penosa a execução da tarefa e aumentando a possibilidade de erros. Este conflito topológico traduz um tipo de incompatibilidade entre pólos da interação e mostra que, neste momento, a estratégia operatória do bancário assume uma função de prótese cognitiva para resolver um problema que ele não criou.

Estes aspectos ligados às dificuldades de utilização orientaram outras análises mais finas em termos de indicadores quantitativos de erros registrados quando da verificação dos listings permitindo colocar em correspondência as dificuldades vivenciadas pelos bancários $\mathrm{X}$ tipos de erros cometidos.

Globalmente, os resultados mostram problemas que caracterizam uma abordagem de inspirą̧ão tecnicista de software que relega a uma importância secundária o savoir-faire dos bancários $\mathrm{e}$ as exigências técnicas da tarefa na medida em que estas não foram satisfatoriamente consideradas quando da sua concepção do software bancário.

\section{4 - Conclusão}

Este estudo, de caráter exploratório, permitiu propor um certo número de recomendações no sentido de suprimir ou reduzir os indicadores de disfuncionamento constatados. Tomandose em conta a experiência dos usuários, foram propostas recomendações quanto aos aspectos de apresentação das informações, navegação nas telas, homogeneidade na codificação da linguagem, compatibilidade entre a entrada e saída das informações etc.

Os resultados, alguns deles servindo de fontes para análises mais finas, constituíram-se na matéria-prima para um projeto de reavaliação e reconcepção dos softwares utilizados na agência bancária. Neste sentido, superar os problemas de interação constatados implicou em considerar a atividade, as características e o savoir-faire dos bancários envolvidos com a tarefa. Identificar a lógica de utilização, desde sua gênese, e apreender o processo mental pelo qual o bancário estrutura suas atividades deve ser um dos objetivos principais num projeto de concepçãoavaliação em informática de inspiração antropocêntrica. De um modo geral, os resultados obtidos eram desconhecidos do 
setor de informática da agência revelando problemas de comunicação entre os projetistas e usuários dos softwares. As dificuldades e os erros dos bancários descritos pela pesquisa são, antes de tudo, o resultado de um processo de concepção que marginaliza a experiência do usuário.

Como uma primeira abordagem do trabalho bancário informatizado da agência, o estudo estabeleceu novas bases para a sua continuação apontando a necessidade de se realizar análises mais finas e, sobretudo, verificar em que medida os resultados obtidos nesta etapa são generalizáveis para outras atividades informatizadas do banco.

\section{Nota}

Alguns estudos (Zamberlan \& Salerno, 1979; Blass, 1988; Ferreira, 1992; Codo et al. 1993) permitem identificar traços comuns do trabalho bancário. Eles são úteis, do ponto de vista metodológico, na medida que fornecem um quadro de referência, um ponto de partida para verificar semelhanças e diferenças entre diferentes contextos do trabalho bancário.

\section{Referências Bibliográficas}

BASTIEN, C. (1991). Validation de critères ergonomiques pour l'évaluation d'interfaces utilisateurs. Rapports de Recherche, no 1427, INRIAROCQUENCOURT.
BLASS, L.M.S. (1988). Trabalho bancário: $O$ (re)fazer de todo instante. São Paulo: SEEB-SP.

BLASS, L.M.S. (1992). Automação bancária: Práticas e representações. Comunicação no XVI Encontro Anual da ANPOCS, Caxambú - MG, 21 a 24.11.1992.

BRUMENT, J.M. (1986). Informatique et évolution des métiers: Conduite du changement dans les banques assurances. In Ergonomie et conditions de travail en informatique, pp. 58-64, R. PATESSON, Editions de l'Université de Bruxelles.

CODO, W.; SAMPAIO, J.J.C.; HITOMI, A.H. \& BAUER, M. (1993). $O$ "mal-estar do trabalho vazio"em bancários. Jornal Brasileiro de Psiquiatria, Vol. 42, supl. 1, março 1993.

FERREIRA, M.C. \& WEILLFASSINA, A. (1996). Le statut théorique et méthodologique des schémas d'actions dans l'analyse des activités bancaires informatisées. Actes du Congrès d'Ergonomie et Informatique Avancée Biarritz - France.

FERREIRA, M.C. (1992). Carga de trabalho bancário e saúde: Um estudo ergonomico com os avaliadores de penhor da Caixa Econômica Federal do DF. Dissertação de Mestrado, Departamento de Psicologia Social e Trabalho, Universidade de Brasilia - UnB, Brasília - DF. 


\section{PRODUÇĀO}

GOLLAC, M. (1988). Dans les banques, une informatisation intensive mais traditionnelle. In La Lettre d'Information de l'Agence Nationale pour l'Amélioration des Conditions de Travail. ANACT, Novembre, $n^{\circ} 135, \mathrm{p}$. 4.

GUÉRIN, F. LAVILLE A., DANIELLOU F., DURRAFOURG J. \& KERGUELLEN A. (1991). Comprendre le travail pour le transformer. La pratique de l'ergonomie. Collection Outils et Méthodes, Editions ANACT.

KARNAS, G. \& SALENGROS, P. (1983). L'ergonomie: adapter ?. In $L a$ Revue Nouvelle, no 3, p. 272-281.

KARNAS, G.; MESTDAGH, F. \& VAN DE LEMPUT, C. (1987). Evaluation ergonomique de la relation HommeMachine: Ergonomie des logiciels dans le secteur tertiaire. Rapport de Recherche, Lab. de Psychologie Industrielle et Commerciale, Université de Bruxelles.

RABARDEL, P. (1995). Les hommes \& les technologies. Approche cognitive des instruments contemporains. Armand Colin, Paris.

REUTER, H.J. (1984). Evolution technologique dans la banque et l'assurance: Influences sur la clientèle et les employés. Berlin, Fondation Européenne pour l'Amélioration des Conditions de Vie et de Travail.
ROCHA, J.B.V. (1989). Financial speculation, high-technology and labor: The process of automation in Brazil's bankin industry 19641986 (1986). Thesis submitted in partial fulfillment of the requirements for the degreee of Doctor of Philosophy. University of Wisconsin, Madison, USA.

ROGARD, V. \& VALLERY, G. (1993). L'ergonomie cognitive dans le processus d'informatisation des activités tertiaires. In J.C. Sperandio, $L$ 'ergonomie dans la conception des projets informatiques. Octares Editions, p. $265-295$.

SCAPIN, D.L. (1986). Guide ergonomique de conception des interfaces homme-machine. Rapports Techniques, no 77, INRIA-ROCQUENCOURT.

SCAPIN, D.L. (1991). Vers des outils formels de description des tâches orientes conception d'interfaces. Rapports de Recherche, no 893, INRIAROCQUENCOURT.

SÉBILLOTE, S. (1993). Schémas d'actions acquis par l'expérience dans les représentations mentales des opérateurs: leurs utilisations et la construction de nouveaux schémas. In $\mathrm{A}$. WEILLFASSINA; P. RABARDEL \& D. DUBOIS Représentations pour l'Action. Octares Editions, Toulouse, p. 42-57. 
THEUREAU, J. (1993). Une approche de la conception des systèmes informatiques interactifs. In Génie Logiciel et Systèmes Experts, no 33 , décembre. $\mathrm{p}$ 4-10.

VALLERY, G. \& CHARVADOINE, R. (1988). L'informatique à la Caisse d'Erpagne de Paris. In La Lettre d'Information de l'Agence Nationale pour l'Amélioration des Conditions de Travail. ANACT, Novembre, no 135.

ZAMBERLAN, F.L. \& SALERNO, M.S. (1979). O trabalho nos bancos. Trabalho de formatura, Departamento de Engenharia de Produção da Escola Politécnica da Universidade de São Paulo. São Paulo: Mimeo 